\title{
APLIKASI PENGELOLAAN LAHAN KELAPA SAWIT (APLKS) BERBASIS INFORMATION SYSTEM INTERACTIVE MAP DI KEBUN TINJOWAN
}

\author{
Surya Ningsih, Dewi Mutiara, Rizqan Khalish, Muhammad Ridha Syafii Damanik \\ Jurusan Pendidikan Geografi, Fakultas Ilmu Sosial \\ Universitas Negeri Medan \\ JI. Wiliem Iskandar Psr V Medan Estate-Medan Kotak Pos No. 1589 Medan 20221 \\ E-mail: mridhadamanik@unimed.ac.id
}

\begin{abstract}
The need for an easy and fast information system is a demand that must be answered in the current management of oil palm plantations. Application Development of Palm Oil Land Management (APLKS) based on Information System Interactive Map is one way to answer these demands. This research was conducted at Palm Oil Plantation of Tinjowan, North Sumatera Province. The purpose of this research is to know the accuracy of mapping and application of Palm Land Management Application (APLKS) in Tinjowan Palm Oil Plantation. The method used in this research is descriptive qualitative. Data collection technics used are documentary studies, direct observation, and application development. The analysis result shows that the level of Overal Accuracy (overall accuracy) mapping is $94,64 \%$. The results of application implementation measurement indicate that this application is very helpful for companies in palm oil land management especially in the ease and speed of information access location and condition of plantation.
\end{abstract}

Keywords: Application Development of Palm Oil Land Management, Interactive Map

\begin{abstract}
Abstrak
Kebutuhan akan sistem informasi yang mudah dan cepat merupakan tuntutan yang harus dijawab pada pengelolaan kebun kelapa sawit saat ini. Pengembangan Aplikasi Pengelolaan Lahan Kelapa Sawit (APLKS) berbasis Information System Interactive Map merupakan salah satu cara untuk menjawab tuntutan tersebut. Penelitian ini dilakukan di Perkebunan Kelapa Sawit Tinjowan Provinsi Sumatera Utara. Tujuan penelitian ini adalah untuk mengetahui akurasi pemetaan dan penerapan Aplikasi Pengelolaan Lahan Kelapa Sawit (APLKS) di Perkebunan Kelapa Sawit Tinjowan. Metode yang digunakan dalam penelitian ini adalah deskriptif kualitatif. Teknik pengumpulan data yang digunakan adalah studi dokumenter, observasi langsung, dan pengembangan aplikasi. Hasil analisis menunjukkan bahwa tingkat Overal Accuracy (akurasi keseluruhan) pemetaan sebesar $94,64 \%$. Hasil pengukuran penerapan aplikasi menunjukkan bahwa aplikasi ini sangat membantu perusahaan dalam pengelolaan lahan kelapa sawit khususnya dalam kemudahan dan kecepatan akses informasi letak dan kondisi perkebunan.
\end{abstract}

Kata kunci : Aplikasi Pengelolaan Lahan Kelapa Sawit, Peta Interaktif

\section{PENDAHULUAN}

Kelapa sawit (Elaeis) adalah tumbuhan industri penting penghasil minyak masak, minyak industri, maupun bahan bakar (biodiesel). Kelapa sawit juga merupakan salah satu komoditi perkebunan yang menduduki posisi cukup penting sebagai sumber devisa non migas bagi Indonesia.
Luas areal lahan tanaman kelapa sawit Indonesia pada tahun 2016 dengan angka estimasi sebesar 11.672.861 Ha. Kebutuhan akan minyak kelapa sawit terus meningkat sejalan dengan meningkatnya standar hidup manusia sehingga memiliki prospek yang cerah, hal ini dapat dilihat dari nilai ekspor komoditas perkebunan pada tahun 
2015 terdata di bulan September jumlah ekspor komoditas minyak sawit sebanyak 19.043.783 ton. (Direktorat Jenderal Perkebunan, dan Statistik Perkebunan Indonesia Komoditas Kelapa Sawit 20142016).

Produktivitas industri kelapa sawit Indonesia masih belum sebaik Malaysia yang potensi alamnya jauh lebih kecil. Salah satu penyebabnya adalah efektivitas manajemen pengelolaan perkebunan kelapa sawit. (Fauzi, 2012). Ada beberapa faktor yang penting dalam menunjang pengelolaan perkebunan kelapa sawit yang efektif diantaranya adalah ketersediaan informasi yang akurat dan memadai untuk kegiatan operasional perkebunan (Akmal, 2017).

Kebun Tinjowan salah satu perusahaan yang mengelola tanaman kelapa sawit yang berlokasi di Sumatera Utara dengan luas lahan 4.531,32 Ha (Kantor Unit Usaha Tinjowan, 2017). Saat ini pengolahan data tanaman kelapa sawit di kebun Tinjowan telah menggunakan komputer, hanya saja belum menggunakan perangkat lunak pengolah data yang dibuat khusus untuk kegiatan tersebut. Perangkat lunak pengolah data yang digunakan saat ini adalah Microsoft Office Excel. Dalam operasionalnya ada beberapa kelemahan yang ditemui, baik dalam entry data, proses, maupun output. Selain itu, aplikasi ini juga mempunyai kelemahan dalam memberikan informasi tentang lokasi keberadaan lahan kelapa sawit yang dikelola oleh kebun Tinjowan baik tanaman yang sehat maupun yang terserang penyakit. Informasi yang dibutuhkan adalah letak lokasi perkebunan, luas perkebunan, areal tanaman rusak dan areal tanaman produktif, dan lain-lain. Hal ini mengakibatkan keterlambatan pengolahan dan informasi data yang pada akhirnya, mengakibatkan sulitnya mendapatkan data terbaru bagi semua pihak yang membutuhkan terutama dalam menentukan perencanaan tanaman agar lebih optimal dalam mengoperasionalkannya.

Sehubungan dengan hal tersebut maka perlu di rancang suatu Sistem Informasi Geografis (SIG) yang khusus untuk mengelola data yang memiliki informasi spasial (bereferensi keruangan). Teknologi SIC (Sistem Informasi Geografis) merupakan suatu teknologi mengenai pemetaan wilayah yang memiliki kemampuan dalam memanipulasi data-data di lapangan menjadi sebuah data berbentuk peta yang dapat memudahkan pengguna untuk mengetahui sebuah posisi atau letak suatu tempat beserta informasi didalamnya (Prahasta, 2006). Selanjutnya Damanik dkk (2018) mengemukakan bahwa Sistem Informasi Geografis telah mengalami perkembangan yang cukup pesat dan menjadi solusi dalam memecahkan masalah keruangan. Sistem SIG dapat diintegrasikan dengan peta berbasis Google Maps, yang data petanya dapat selalu diupdate oleh pihak perkebunan menyesuaikan keadaan yang ada di lapangan.

\section{METODOLOGI}

Penelitian ini dilakukan di Kebun Tinjowan Kecamatan Ujung Padang, Kabupaten Simalungun. Penelitian ini dilaksanakan dalam beberapa tahapan, yaitu:

1) Pengumpulan data dan survei lapangan. Pengumpulan data dapat dilakukan dengan melakukan survei lapangan, hal ini bertujuan untuk melihat kebenaran data-data dokumenter dengan data-data yang ada di lapangan sesuai dengan keutamaan dalam penelitian.

2) Entry data dalam aplikasi ArcGIS. Setelah seluruh data didapat dari hasil survei lapangan, maka tahap selanjutnya datadata tersebut diolah ke dalam data peta digital sesuai dengan titik koordinat lokasi perkebunan.

3) Penyusunan aplikasi

a) Merancang halaman home admin.

b) Merancang manajemen data perkebunan

4) Uji aplikasi dan perbaikan. Pengujian dan perbaikan aplikasi yang dilakukan dalam penelitian ini meliputi 3 aspek pengujian (1) Kemudahan dalam menggunakan aplikasi (2) Keakuratan data peta interaktif dengan data perkebunan dan (3) Kebutuhan akan penggunaan aplikasi.

5) Penggunaan sistem APLKS berbasis sistem informasi peta interaktif.

Aplikasi ini dijalankan melalui dua sistem yaitu sistem terbuka dan sistem tertutup. Sistem terbuka merupakan sistem yang hanya bisa dijalankan oleh pihak terkait di dalam perkebunan. Pihak terkait dapat mengentry data-data perkebunan ke dalam aplikasi ini dan dapat memberikan informasi kepada pihak luar. Sedangkan sistem tertutup merupakan sistem yang menyajikan informasi berkaitan dengan perkebunan 
kepada pihak luar. Aplikasi ini dapat digunakan dengan membuka laman web yang diberikan oleh user/pihak perkebunan terhadap pihak yang membutuhkan.

Adapun teknik pengumpulan data yang dilakukan dalam penelitian ini adalah

1. Teknik Studi Dokumenter

Studi dokumenter dilakukan dengan cara mengumpulkan data yang berhubungan dengan topik penelitian. Melalui studi dokumenter ini diperoleh data yang terdapat dari instansi-instansi yang berkaitan seperti Kantor Perkebunan Tinjowan. Data yang terkumpulkan antara lain data tentang keadaan tanaman kelapa sawit seperti: Peta kebun kelapa sawit, blok tanam, tanaman terserang hama, tanaman terserang penyakit, dan jadwal pemberian pupuk tanaman.

2. Teknik Observasi Langsung

Pengecekan lapang dengan menggunakan GPS (Global Positioning System) bertujuan untuk mengetahui koordinat daerah penelitian dan juga untuk pengambilan titik koordinat tiaptiap batas lahan kebun kelapa sawit.

Teknik Analisis data yang dilakukan dalam penelitian ini adalah analisis data secara deskriptif kualitatif, yaitu:

1. Pengolahan data

Pengolahan data dilakukan dengan menginput data keadaan tanaman kelapa sawit dari instansi dan mengestimasi luasan dan jumlah tanaman untuk dilakukan perawatan ataupun tanaman ulang kembali. Pengolahan ini dilakukan dengan menggunakan software ArcGIS untuk pembuatan point untuk simbol pohon kelapa sawit, polygon untuk area perkebunan, dan database. Setelah itu eksport data yang sudah diolah menjadi format KML (Keyhole Markup Language) agar dapat dibaca oleh sistem google map. 2. Implementasi WebCIS

Fase ini melakukan implementasi dengan mendesain website via google map dari hasil analisis kebutuhan sistem perencanaan informasi.

3. Pengujian dan hasil analisis

Dalam fase ini pengujian dan hasil analisis dilakukan melalui tiga aspek yaitu aspek kemudahan dari penggunaan, aspek keakuratan atau kebenaran data dan aspek kebutuhan penggunaan aplikasi. Ketiga aspek ini perlu ditinjau lebih lanjut untuk mengetahui sistem yang seharusnya perkebunan butuhkan pada saat ini.

\section{HASIL DAN PEMBAHASAN}

Hasil penelitian ini adalah menciptakan suatu aplikasi berupa webGIS. WebGIS adalah suatu perangkat lunak SIC atau pemetaan secara digital yang menggunakan jaringan internet sebagai media komunikasi yang berfungsi untuk memberikan informasi berupa luas lahan, jumlah tanaman, nama blok tanaman, tahun tanam, dan usia tanaman. Penelitian ini dilakukan secara interpretasi digital berbasis SIC dengan menggunakan citra landsat-8 OLI TIRS. Interpretasi citra digital dengan citra landsat-8 OLI TIRS dilakukan untuk melihat luas lahan areal lokasi penelitian dan jumlah tanaman. Adapun hasil interpretasi citra digital dan hasil observasi lapangan adalah sebagai berikut:

Tabel 1. Data Interpretasi Citra Landsat-8 OLI TIRS Kebun Tinjowan

\begin{tabular}{|c|c|c|c|}
\hline No. & Nama Blok & Luas Lahan & Jumlah Tanaman \\
\hline 1. & В 02 & 59,36 & 9,211 \\
\hline 2. & B 05 & 83,60 & 11,898 \\
\hline 3. & B 12 & 125,32 & 2,15 \\
\hline 4. & B 13a & 128,85 & 20,865 \\
\hline 5. & B $13 b$ & 43,15 & 6,500 \\
\hline 6. & B 16 & 52,85 & 8,120 \\
\hline 7. & B 96 & 56,72 & 8,902 \\
\hline 8. & B 99a & 92,86 & 15,011 \\
\hline 9. & B 99b & 93,21 & 15,231 \\
\hline 10. & B 99c & 14,65 & 2,245 \\
\hline \multirow[t]{2}{*}{11.} & B $99 \mathrm{~d}$ & 12,05 & 1,785 \\
\hline & Total & 762,62 & \\
\hline
\end{tabular}


Tabel 2. Data Hasil Observasi di Kebun Tinjowan

\begin{tabular}{cccccc}
\hline No. & $\begin{array}{c}\text { Nama } \\
\text { Blok }\end{array}$ & $\begin{array}{c}\text { Luas Lahan } \\
/ \text { Ha }\end{array}$ & $\begin{array}{c}\text { Jumlah } \\
\text { Tanaman }\end{array}$ & Usia Tanam/tahun & Kerusakan \\
\hline 1. & B 02 & 58,6 & 9,211 & 16 & 785 \\
\hline 2. & B 05 & 83,67 & 11,898 & 13 & 489 \\
\hline 3. & B 12 & 84,04 & 2,15 & 6 & 56 \\
\hline 4. & B 13a & 132,74 & 20,865 & 5 & 10 \\
\hline 5. & B 13b & 42,04 & 6,500 & 5 & 0 \\
\hline 6. & B 16 & 52,8 & 8,120 & 2 & 0 \\
\hline 7. & B 96 & 57,621 & 8,902 & 22 & 631 \\
\hline 8. & B 99a & 91,44 & 15,011 & 19 & 153 \\
\hline 9. & B 99b & 91,74 & 15,231 & 19 & 208 \\
\hline 10. & B 99c & 15,04 & 2,245 & 19 & \\
\hline 11. & B 99 d & 12,36 & 1,785 & 19 & \\
\hline & Total & 722,09 & & & 19 \\
\hline
\end{tabular}

Sumber : Kantor Unit Usaha Tinjowan. 2017. Data inventaris pohon tidak produktif dan pohon produktif bulan Mei 2017.

Tabel 1. dan tabel 2. Merupakan isian informasi yang akan disajikan ke dalam aplikasi webGIS, dengan cara membandingkan hasil lapangan dengan hasil interpretasi citra secara digital. Kedua data ini merupakan data utama yang menjadi acuan dalam pembuatan aplikasi berbasis webGIS.

$O A(\%)=\frac{\text { jumlah data hasil lapangan }}{\text { jumlah sampel uji interpretasi }} \times 100$

\section{Keterangan: $\mathrm{OA}=$ Overall Accuracy}

Nilai Overal Accuracy (akurasi keseluruhan) banyaknya jumlah data hasil lapangan (data sekunder) dibandingkan dengan data sampel uji interpretasi yang dilakukan untuk semua blok di Kebun Tinjowan. akurasi keseluruhan yang diperoleh untuk menguji tingkat akurasi menunjukkan nilai $94,64 \%$ yang berarti $94,64 \%$ data yang ada pada hasil data terakurasi dengan benar untuk tingkat akurasi dari luas lahan tiap blok yang ada di Kebun Tinjowan.

WebGIS memiliki beberapa keuntungan dalam penggunaannya dibandingkan dengan web lainnya, diantaranya yaitu (1) Dapat menyajikan peta yang interaktif, (2) Dapat dijangkau dengan mudah dan dimana saja, (3) Dapat dijangkau dengan orang banyak dan biaya lebih murah, (4) Pengguna tidak perlu lagi menggunakan perangkat lunak khusus, cukup menggunakan internet (Prahasta, 2006).

WebGIS dalam penelitian ini dapat menyajikan suatu tampilan peta yang berupa peta interaktif. Peta interaktif adalah penyajian peta yang mudah digunakan dan data-data yang disajikan dalam webG/S berupa data-data yang terbaru atau up to date. 


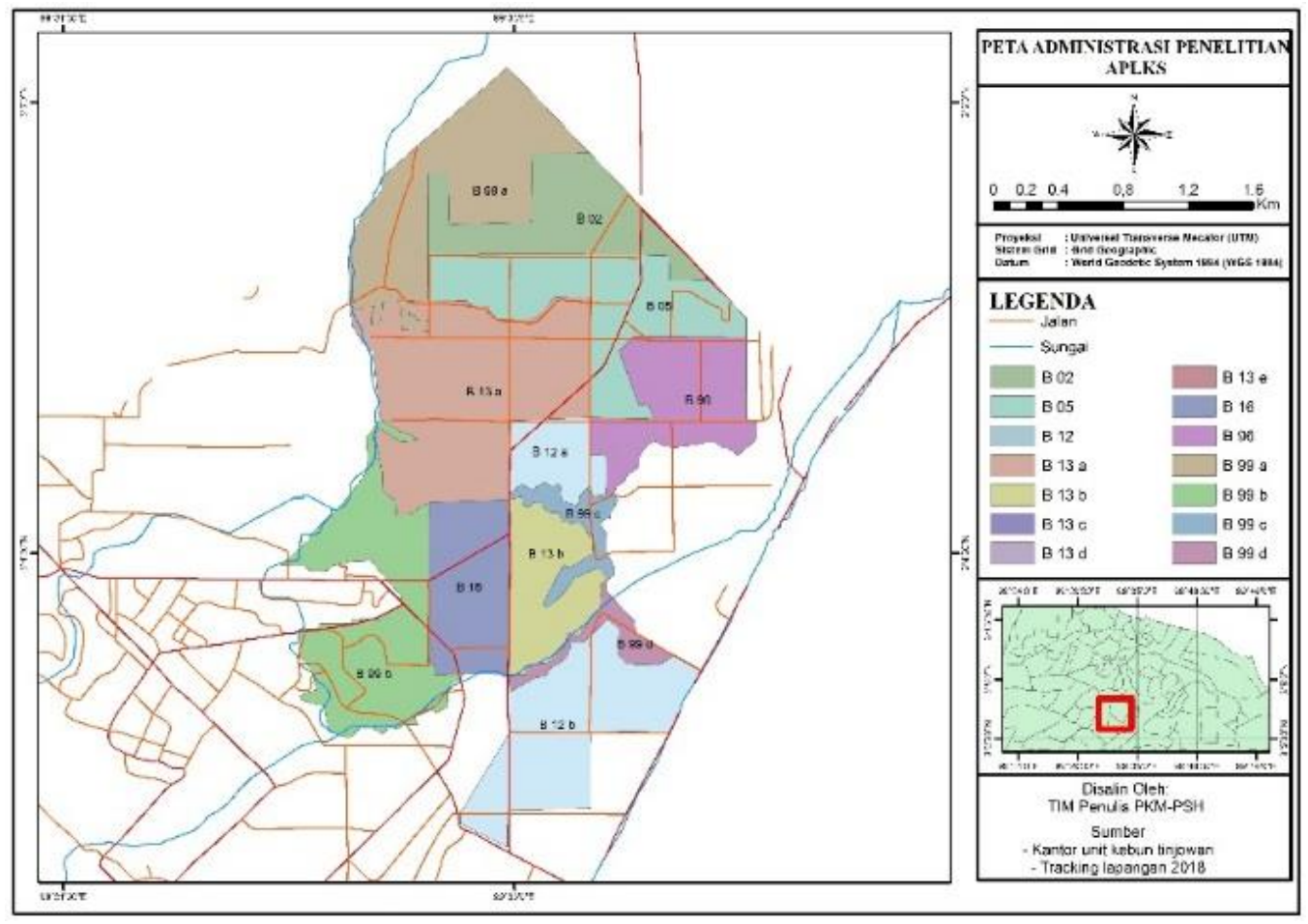

Gambar 1. Peta Lokasi Penelitian PKM-PSH

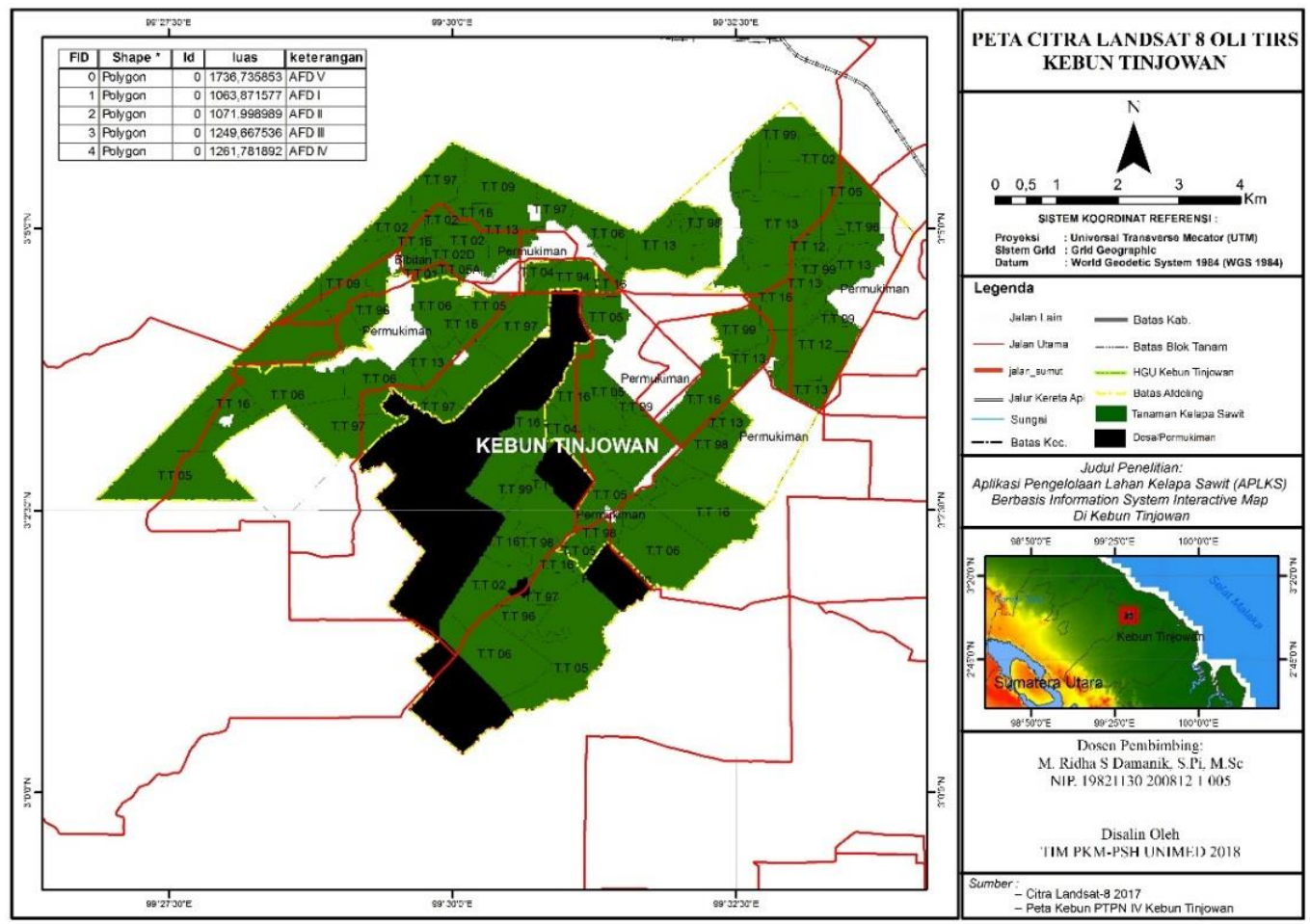

Gambar 2. Peta Citra Landsat-8 OLI TIRS Kebun Tinjowan 


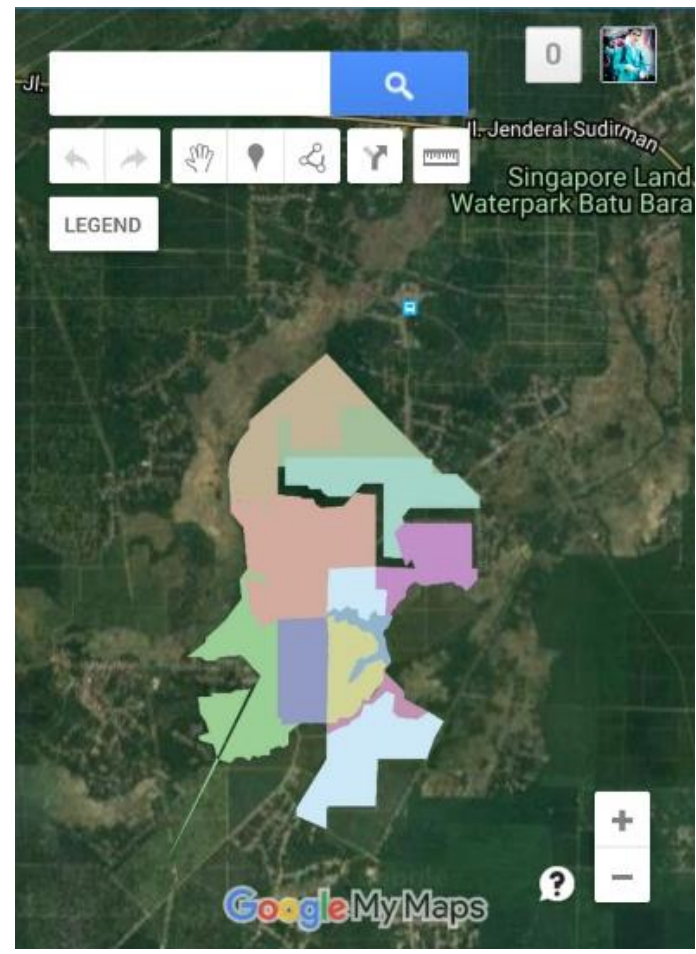

Gambar 3. Tampilan Aplikasi Pengelolaan Lahan Kelapa Sawit

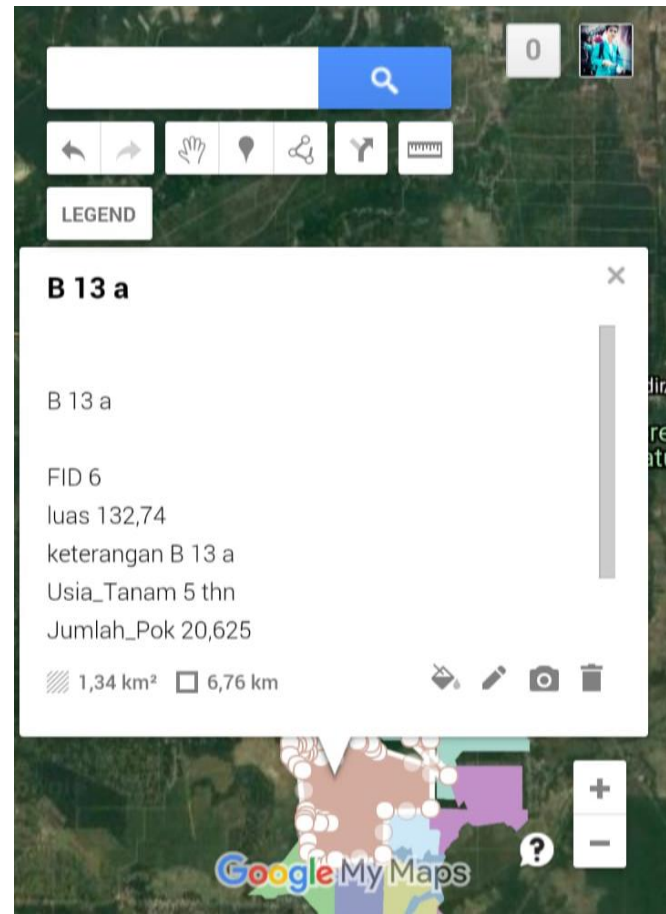

Gambar 3. Tampilan Informasi Aplikasi Pengelolaan Lahan Kelapa Sawit Di Sajikan Dalam Interaktif Map 


\section{KESIMPULAN DAN SARAN}

Berdasarkan hasil dan pembahasan penelitian ini maka dapat disimpulkan:

1) Hasil uji akurasi dari pemetaan di lapangan dengan interpretasi dengan menggunakan Citra Landsat -8 OLI TIRS menunjukkan nilai $94,64 \%$.

2) Penelitian ini menciptakan suatu sistem aplikasi berbasis webGIS yang dapat menyajikan informasi berupa peta interaktif

3) Peta interaktif akan memberikan informasi yang dibutuhkan sesuai dengan kebutuhan dari pengguna, seperti luas lahan, jumlah tanaman, nama blok tanaman, tahun tanam, dan usia tanaman.

4) Penggunaan aplikasi webGIS ini menggunakan tampilan aplikasi via google map yang berbasis webGIS.

5) Penelitian ini dilakukan dengan pengukuran langsung di lapangan dan interpretasi secara digital dengan menggunakan Citra Landsat-8 OLI TIRS. Berdasarkan kesimpulan diatas, adapun saran yang disampaikan penulis adalah sebagai berikut:

1) Perlu adanya penelitian tentang interpretasi citra digital yang berkelanjutan lagi.

2) Perlu adanya penelitian lanjutan yang berkaitan dengan penelitian ini, agar lebih memperbaiki lagi hasil berkelanjutannya

\section{DAFTAR PUSTAKA}

Akmal. Faisal, dkk. 2017. Sistem Informasi Pengelolaan Perkebunan Kelapa Sawit Berbasis Web CIS, Jurnal Pengembangan Teknologi Informasi dan Ilmu Komputer Vol. 2.

Damanik, M. R. S., Nurman, A., Restu, R., \& Berutu, N. (2018). Tsunami risk analysis with run-up variation scenario based on modeling of Geographic Information System on Sibolga City North Sumatera. International Journal of Engineering and Technology(UAE), 7(2.13 Special Issue https://doi.org/10.14419/ijet.v7i2.29 .13648

Direktorat Jenderal Perkebunan dan Statistik Perkebunan Indonesia Komoditas Kelapa Sawit 2014 - 2016. 2015. Jakarta: (Online).
Fauzi,Y. dkk. 2012. Kelapa Sawit Penebar Swadaya. Jakarta: (Online). hlm-168. Diakses 06 maret 2017.

Kantor Unit Usaha Tinjaowan. 2017. produksi TBS per tahun. PTPN IV Tinjowan.

Kantor Unit Usaha Tinjaowan. 2017. Data inventaris pohon tidak produktif dan pohon produktif bulan Mei 2017. PTPN IV Tinjowan.

Prahasta, Eddy. 2006. Sistem Informasi Geografis Membangun Aplikasi WEB-based GIS dengan MapServer. Informatika. Bandung. 
